\title{
ACT-FASTER, a Prospective Cohort Study Exploring Treatment Patterns with Fulvestrant and Exemestane in Postmenopausal Patients with Advanced Hormone Receptor-Positive Breast Cancer under Real-Life Conditions in Germany
}

\author{
Nicolai Maass ${ }^{a}$ Helmut Ostermann $^{b}$ Kurt Possinger ${ }^{c}$ Peter Klein ${ }^{d}$ \\ Hans Tesch $^{\mathrm{e}}$ Lars Mühlenhoff $^{f}$ Dirk Bauerschlag ${ }^{\mathrm{a}}$ \\ ${ }^{a}$ Klinik für Gynäkologie und Geburtshilfe, UKSH, Kiel, ${ }^{b}$ Medizinische Klinik und Poliklinik III, Klinikum der Universität \\ München-Großhadern, München, ' ${ }^{\top}$ Medizinische Klinik mit Schwerpunkt Onkologie und Hämatologie, Charité \\ Campus Mitte, Berlin, dd.s.h. Statistical Services GmbH, Rohrbach, e Onkologische Gemeinschaftspraxis, Frankfurt/M., \\ and ${ }^{\mathrm{f}}$ Medical Affairs, AstraZeneca, Wedel, Germany
}

Keywords

Advanced breast cancer - Fulvestrant - Exemestane .

Endocrine therapy

\begin{abstract}
Background: Endocrine therapy is recommended for the treatment of postmenopausal women with hormone receptor-positive ( $\mathrm{HR}+$ ) advanced breast cancer ( $\mathrm{ABC})$. Methods: ACT-FASTER was a German prospective non-interventional cohort study in postmenopausal women with $\mathrm{HR}+\mathrm{ABC}$ receiving fulvestrant $500 \mathrm{mg}$ as first line $(1 \mathrm{~L})$, second line $(2 \mathrm{~L})$ or third line $(3 \mathrm{~L})$, or exemestane (any line) in the real-world palliative setting. Primary study objectives included the effectiveness of fulvestrant according to line of palliative treatment measured by time to progression (TTP), and real-life data on the epidemiology and management of these patients. Results: Of 498 evaluable patients (mean age 67.5 years), 99\% were estrogen receptor-positive. On study, $86.7 \%$ of patients received fulvestrant $500 \mathrm{mg}$ and $13.3 \%$ exemestane. Median TTP was 9.7 months in patients receiving fulvestrant $1 \mathrm{~L} ; 6.8$ months for $2 \mathrm{~L}$; and 6.7 months for $3 \mathrm{~L}$. The comparison between fulvestrant $1 \mathrm{~L}$ palliative treatment and $2 \mathrm{~L}$ or $3 \mathrm{~L}$ showed that early initiation of treatment prolonged TTP (hazard ratio 1.26; 95\% confidence interval 1.08-1.48). Treat-
\end{abstract}

๑) 2019 S. Karger AG, Basel ments were well tolerated. Conclusion: Fulvestrant $500 \mathrm{mg}$ was administered successfully to patients under daily practice conditions, and both medications were well tolerated. TTP was longest in patients treated with fulvestrant $500 \mathrm{mg}$ $1 \mathrm{~L}$ compared with $2 \mathrm{~L}$ and $3 \mathrm{~L}$ in the palliative care setting.

(c) 2019 S. Karger AG, Basel

\section{Introduction}

Breast cancer is the most common malignancy in women, with more than 70,000 new cases and about 16,800 deaths every year in Germany [1]. According to the 2018 national guidelines on the diagnosis and treatment of breast cancer by the Arbeitsgemeinschaft Gynäkologische Onkologie, endocrine therapy (ET) represents the clinical standard of care for postmenopausal women with advanced breast cancer (ABC) with positive/ unknown hormone receptor $(\mathrm{HR}+/-)$ status, unless the disease is acutely life-threatening. However, the optimum endocrine treatment for $\mathrm{HR}+\mathrm{ABC}$ remains unclear [2, 3]. Prior ETs (used in the adjuvant setting) should be considered before initiation of any ET in the palliative setting. Important aspects of treatment for these patients are quality of life and treatment compliance [4]. 
Fulvestrant, a selective estrogen receptor (ER) downregulator, is approved for the treatment of postmenopausal patients with $\mathrm{HR}+\mathrm{ABC}$ after prior anti-estrogen treatment. In the CONFIRM trial, fulvestrant $500 \mathrm{mg}$ was associated with a statistically significant increase in progression-free survival (PFS) versus fulvestrant $250 \mathrm{mg}$ along with no increased toxicity. Fulvestrant $500 \mathrm{mg}$ was subsequently approved in Europe for $\mathrm{HR}+\mathrm{ABC}$ in postmenopausal patients $[5,6]$.

Exemestane, a steroidal aromatase inhibitor (AI), has been studied in the metastatic setting in its approved dose of $25 \mathrm{mg}$ once daily in randomized studies in the first line $(1 \mathrm{~L})[4,7]$ and second line $(2 \mathrm{~L})[8]$, and was evaluated as further-line treatment in a number of non-comparative studies [9]. Treatment benefit with exemestane was shown to be greater early in the treatment sequence compared with later [4].

Data on clinical benefit as a function of palliative therapy line for fulvestrant $500 \mathrm{mg}$ were not available at the beginning of this non-interventional study (NIS), as the only 2 large randomized studies with this dosage were carried out in the $1 \mathrm{~L}$ setting $[10,11]$.

This study focused on the effectiveness and healthcare resource use data of ET in the palliative care setting under real-life conditions in Germany.

\section{Methods}

\section{Study Design}

This was a multicenter, prospective, observational NIS in Germany to directly compare the effectiveness of treatment with fulvestrant $500 \mathrm{mg}$ according to line of palliative treatment (i.e., $1 \mathrm{~L}$ vs. $2 \mathrm{~L}$ vs. third-line ( $3 \mathrm{~L})$ ), and to gather epidemiological and disease management data on treatment with fulvestrant and exemestane under real-life conditions in the palliative care setting. The study was approved by the Independent Ethics Committee at the Faculty of Medicine at Aachen University (EK 069/10) and performed in accordance with the Declaration of Helsinki and the International Conference on Harmonization/Good Clinical Practice. Additional ethics committee opinions were sought for any protocol amendments. Written informed consent was obtained from all patients.

\section{Study Population}

Postmenopausal patients aged $\geq 18$ years who had histologically confirmed ER-positive (ER+) locally advanced or metastatic breast cancer were eligible for enrolment in the study. The initial decision to start patients on fulvestrant $500 \mathrm{mg}$ or exemestane was at the discretion of the treating physician and was taken according to the standard of current best medical practice. Treatment was initiated prior to study enrolment; patients could be included from between day 1 and day 28 of starting treatment. The first patient was included on 09 August 2010, and the final patient's last visit was on 30 November 2013. For the purposes of the study, women were considered to be postmenopausal if they: i) were aged $\geq 60$ years with natural menopause (i.e., no menses for $>1$ year); ii) had follicle-stimulating hormone and estradiol levels in the postmenopausal range, or iii) had undergone a bilateral oophorectomy.
Exclusion criteria included patients being eligible for curative therapy, having known hypersensitivity to fulvestrant or exemestane or any compounds of the drugs, having received prior treatment with any study drugs, having acute life-threatening disease, or having received prior palliative chemotherapy. Prior fulvestrant treatment was permitted in the exemestane arm. Prior exemestane treatment was permitted in the fulvestrant arm.

Although the original aim was to recruit 660 patients $(n=165$ per arm), recruitment for the fulvestrant $3 \mathrm{~L}$ and exemestane groups was considerably slower than for the fulvestrant $1 \mathrm{~L}$ and $2 \mathrm{~L}$ groups. The protocol was therefore amended in March 2012 to recruit approximately 570 patients during a 30 -month period (anticipated $n=200$ in each of the $1 \mathrm{~L}$ and $2 \mathrm{~L}$ groups, $n=90$ in the 3 L group, and $n=80$ in the exemestane group).

\section{Study Outcomes}

The study had 2 co-primary objectives: the first was to compare the effectiveness of fulvestrant (in terms of time to progression (TTP), defined as time from first documented dose of study treatment to date of progression as judged by the investigator) as a function of the line of palliative treatment, and the second was to collect and explore real-life data on the epidemiology and management of patients treated with fulvestrant or exemestane. The study had multiple secondary objectives; these included the collection and exploration of real-life effectiveness data. In this context, patient outcomes included TTP (for patients treated with exemestane), overall survival (OS), PFS (defined as time from first documented study treatment to date of progression or death), objective response rate (ORR), and clinical benefit rate (CBR; defined as the proportion of patients who experienced an objective response (OR) or stable disease for $\geq 24$ weeks). Median time to OS is not included in the current report because this endpoint was not reached during the observational period of the study.

\section{Interventions}

As this was an NIS, no randomization was implemented. Patients were allocated to 1 of 4 cohorts: $1 \mathrm{~L}, 2 \mathrm{~L}, 3 \mathrm{~L}$ palliative treatment with fulvestrant $500 \mathrm{mg}$, or any line palliative treatment with exemestane $25 \mathrm{mg}$. Dosage and administration of the drugs were per the Summary of Product Characteristics $[5,12]$. Patients received either fulvestrant $500 \mathrm{mg}(2 \times 250 \mathrm{mg}$ intramuscularly on days $0,14,28$, then every 4 weeks) or once-daily exemestane orally. Patients were allocated to groups by the treating physician according to documented previous therapies until the number defined by sample size calculation was reached. Concomitant therapy and/or medication considered necessary for the patient's safety and wellbeing could be given at the discretion of the investigator and was recorded in the case report form.

\section{Study Assessment}

Data were collected throughout the study during routine clinical treatment and assessments until disease progression or treatment discontinuation for other reasons or 9 months after inclusion of the last patient, whichever occurred first. Patients' demographic and baseline characteristics were collected at study entry. At subsequent follow-up and the study discontinuation visit, details were collected about patients' tumor and endocrine status, adverse events (AEs) and other treatments that they had received (e.g., surgery, radiotherapy). Data on patient discontinuations or deaths were also recorded. The frequency of follow-up visits and any associated management decisions (e.g., diagnostic and/or therapeutic interventions) were determined by the treating physician. In line with NIS requirements, no study-specific visits or interventions were performed. Treatment compliance was assessed in terms of completed documentation. 
Table 1. Demographic and baseline patient characteristics

\begin{tabular}{|c|c|c|c|c|c|}
\hline & $\begin{array}{l}\text { Fulvestrant } \\
1 \text { st line } \\
(\mathrm{n}=176)\end{array}$ & $\begin{array}{l}\text { Fulvestrant } \\
\text { 2nd line } \\
(\mathrm{n}=163)\end{array}$ & $\begin{array}{l}\text { Fulvestrant } \\
\text { 3rd line } \\
(\mathrm{n}=93)\end{array}$ & $\begin{array}{l}\text { Fulvestrant } \\
\text { any line } \\
(\mathrm{n}=432)\end{array}$ & $\begin{array}{l}\text { Exemestane } \\
\text { any line } \\
(\mathrm{n}=66)\end{array}$ \\
\hline \multicolumn{6}{|l|}{ Age, years } \\
\hline Mean \pm SD & $66.8(10.01)$ & $67.2(11.05)$ & $68.6(10.08)$ & $67.4(10.43)$ & $67.7(11.82)$ \\
\hline Min-Max & $45.0-90.0$ & $34.0-91.0$ & $38.0-90.0$ & $34.0-91.0$ & $37.0-85.0$ \\
\hline Median & 68.0 & 69.0 & 70.0 & 69.0 & 72.0 \\
\hline \multicolumn{6}{|l|}{$\mathrm{BMI}, \mathrm{kg} / \mathrm{m}^{2}$} \\
\hline Mean \pm SD & $26.7(5.25)$ & $27.2(5.16)$ & $26.0(5.21)$ & $26.8(5.21)$ & $27.4(4.41)$ \\
\hline Min-Max & $16.4-48.3$ & $18.8-53.4$ & $13.5-44.1$ & $13.5-53.4$ & $19.2-38.6$ \\
\hline Median & 25.9 & 26.6 & 26.0 & 26.1 & 27.6 \\
\hline \multicolumn{6}{|l|}{ ER, n (\%) } \\
\hline Unknown & $0(0)$ & $0(0)$ & $1(1.1)$ & $1(0.2)$ & $0(0)$ \\
\hline Negative & $0(0)$ & $1(0.6)$ & $3(3.2)$ & $4(0.9)$ & $0(0)$ \\
\hline Positive & $176(100)$ & $162(99.4)$ & $89(95.7)$ & $427(98.8)$ & $66(100)$ \\
\hline \multicolumn{6}{|l|}{$\mathrm{PR}, \mathrm{n}(\%)$} \\
\hline Unknown & $1(0.6)$ & $2(1.2)$ & $1(1.1)$ & $4(0.9)$ & $0(0)$ \\
\hline Negative & $20(11.4)$ & $16(9.8)$ & $18(19.4)$ & $54(12.5)$ & $6(9.1)$ \\
\hline Positive & $155(88.1)$ & $145(89)$ & $74(79.6)$ & $374(86.6)$ & $60(90.9)$ \\
\hline \multicolumn{6}{|l|}{ HER2/neu, n (\%) } \\
\hline Unknown & $17(9.7)$ & $36(22.1)$ & $27(29)$ & $80(18.5)$ & $14(21.2)$ \\
\hline Negative & $138(78.4)$ & $102(62.6)$ & $52(55.9)$ & $292(67.6)$ & $40(60.6)$ \\
\hline Positive & $21(11.9)$ & $25(15.3)$ & $14(15.1)$ & $60(13.9)$ & $12(18.2)$ \\
\hline \multicolumn{6}{|l|}{ Metastases, n (\%) } \\
\hline Yes & $152(86.4$ & $142(87.1)$ & $82(88.2)$ & $376(87)$ & $51(77.3)$ \\
\hline No & $24(13.6)$ & $21(12.9)$ & $11(11.8)$ & $56(13)$ & $15(22.7)$ \\
\hline \multicolumn{6}{|c|}{ Location of metastases $^{\mathrm{a}}, \mathrm{n}(\%)$} \\
\hline Bone & $103(58.5)$ & $107(65.6)$ & $56(60.2)$ & $266(61.6)$ & $37(56.1)$ \\
\hline Brain & $6(3.4)$ & $3(1.8)$ & $1(1.1)$ & $10(2.3)$ & $0(0)$ \\
\hline Breast & $0(0)$ & $2(1.2)$ & $0(0)$ & $2(0.5)$ & $2(3)$ \\
\hline Liver & $17(9.7)$ & $24(14.7)$ & $12(12.9)$ & $53(12.3)$ & $7(10.6)$ \\
\hline Lung & $30(17)$ & $27(16.6)$ & $28(30.1)$ & $85(19.7)$ & $7(10.6)$ \\
\hline Lymph nodes & $25(14.2)$ & $27(16.6)$ & $15(16.1)$ & $67(15.5)$ & $8(12.1)$ \\
\hline Other & $15(8.5)$ & $13(8)$ & $8(8.6)$ & $36(8.3)$ & $5(7.6)$ \\
\hline Skin & $7(4)$ & $4(2.5)$ & $4(4.3)$ & $15(3.5)$ & $4(6.1)$ \\
\hline Visceral organs ${ }^{\mathrm{b}}$ & $7(4)$ & $3(1.8)$ & $0(0)$ & $10(2.3)$ & $1(1.5)$ \\
\hline
\end{tabular}

\section{Statistical Methods}

The inclusion of 165 patients per treatment cohort was planned. The sample size calculation for this study was based on the first co-primary objective (effectiveness of fulvestrant $500 \mathrm{mg}$ treatment as a function of line of palliative treatment). Approximately 660 patients were required in order to show that the differences in TTP times according to line of treatment, observed in clinical trials for the $250 \mathrm{mg}$ dose, could be achieved in a real-life setting for the $500 \mathrm{mg}$ dose with a 2-sided log-rank test equality of survival curves at a significance level of 0.05 and a power of $90 \%$. Approximately 165 patients per group were required to show a TTP difference of 2.7 months between $1 \mathrm{~L}$ and $2 \mathrm{~L}$ treatment, and approximately 148 patients to show a TTP difference of 1.8 months between $2 \mathrm{~L}$ and $3 \mathrm{~L}$ line analysis. Therefore, the minimum number of $1 \mathrm{~L}, 2 \mathrm{~L}$, and $3 \mathrm{~L}$ patients required was 165,165 , and 148 , respectively. Thus, to ensure a 1:1:1:1 allocation of patients to the 4 different cohorts, a total sample size of approximately 660 patients was required.

All statistical tests were performed 2-sided at a 5\% level of significance; however, the $p$ values of all statistical tests must be inter- preted only in a descriptive-exploratory way, according to the design of the study. Statistical tests were Fisher's exact test for binary or categorical parameters, Mantel-Haenszel test for ordinal parameters, and Wilcoxon test for numerical parameters. Time to event data were analyzed using the log-rank test, prognostic factors were analyzed using Cox regression analysis checking if proportional hazard assumption is fulfilled. 2-sided confidence intervals (CI) were presented for important parameters. All main analyses were performed according to treatment line for fulvestrant and exemestane patients and were adjusted for the main prognostic factors such as visceral metastases (yes/no), patient age ( $<$ or $\geq 65$ years), receptor status $(\mathrm{ER}+$ and progesterone receptor $(\mathrm{PR})+\mathrm{vs}$. ER+ and PR-unknown), measurable disease (yes/no), last ET (AI or antiestrogen), and response to last endocrine treatment. The analysis of the second co-primary objective of the study (exploration of real-life data on the epidemiology and management of postmenopausal patients with $\mathrm{HR}+\mathrm{ABC}$ ) used descriptive methods only.

Data on effectiveness for exemestane in the different therapy lines in the ABC setting have been generated elsewhere $[4,7-9,13]$. 
Table 2. Real-life data on epidemiology

\begin{tabular}{|c|c|c|c|c|c|c|}
\hline Variable & Schedule & $\begin{array}{l}\text { Group } 1 \\
\text { fulvestrant } \\
1 \text { st line } \\
(\mathrm{n}=176)\end{array}$ & $\begin{array}{l}\text { Group } 2 \\
\text { fulvestrant } \\
2 \text { nd line } \\
(\mathrm{n}=163)\end{array}$ & $\begin{array}{l}\text { Group } 3 \\
\text { fulvestrant } \\
\text { 3rd line } \\
(\mathrm{n}=93)\end{array}$ & $\begin{array}{l}\text { Group } 4 \\
\text { exemestane } \\
\text { any line } \\
(\mathrm{n}=66)\end{array}$ & $\begin{array}{l}\text { Comparison } \\
\text { of groups }{ }^{\mathrm{d}}\end{array}$ \\
\hline BMI, $\mathrm{kg} / \mathrm{m}^{2 \mathrm{a}}$ & $\begin{array}{l}\text { non-miss, } \mathrm{n} \\
\text { mean } \\
\text { SE }\end{array}$ & $\begin{array}{r}176 \\
26.73 \\
0.396\end{array}$ & $\begin{array}{r}163 \\
27.21 \\
0.404\end{array}$ & $\begin{array}{r}93 \\
26.00 \\
0.540\end{array}$ & $\begin{array}{r}66 \\
27.39 \\
0.543\end{array}$ & 3 vs. $4(p=0.042)$ \\
\hline Vascular comorbidity ${ }^{\mathrm{b}}$ & $\begin{array}{l}\text { non-miss, } \mathrm{n} \\
\text { no, } \% \\
\text { yes, } \%\end{array}$ & $\begin{array}{r}176 \\
92.61 \\
7.39\end{array}$ & $\begin{array}{r}163 \\
95.09 \\
4.91\end{array}$ & $\begin{array}{r}93 \\
96.77 \\
3.23\end{array}$ & $\begin{array}{r}66 \\
83.33 \\
16.67\end{array}$ & $\begin{array}{l}1 \text { vs. } 4(\mathrm{p}=0.050) \\
2 \text { vs. } 4(\mathrm{p}=0.007) \\
3 \text { vs. } 4(\mathrm{p}=0.004)\end{array}$ \\
\hline ECOG performance status ${ }^{\mathrm{c}}$ & $\begin{array}{l}\text { non-miss, n } \\
\text { status } 0, \% \\
\text { status } 1, \% \\
\text { status } 2, \% \\
\text { status 3, } \%\end{array}$ & $\begin{array}{r}166 \\
41.57 \\
46.99 \\
7.83 \\
3.61\end{array}$ & $\begin{array}{r}154 \\
42.86 \\
46.10 \\
8.44 \\
2.60\end{array}$ & $\begin{array}{r}85 \\
51.76 \\
44.71 \\
2.35 \\
1.18\end{array}$ & $\begin{array}{r}62 \\
50.00 \\
40.32 \\
8.06 \\
1.61\end{array}$ & 1 vs. $3(p=0.049)$ \\
\hline Employment status $^{c}$ & $\begin{array}{l}\text { non-miss, } \mathrm{n} \\
\text { full-time, } \% \\
\text { part-time, } \% \\
\text { not employed, } \%\end{array}$ & $\begin{array}{r}176 \\
3.41 \\
5.68 \\
90.91 \\
\end{array}$ & $\begin{array}{r}163 \\
4.29 \\
6.13 \\
89.57 \\
\end{array}$ & $\begin{array}{r}93 \\
1.08 \\
5.38 \\
93.55 \\
\end{array}$ & $\begin{array}{r}66 \\
7.58 \\
9.09 \\
83.33 \\
\end{array}$ & 3 vs. $4(\mathrm{p}=0.035)$ \\
\hline $\begin{array}{l}\text { Months since first diagno- } \\
\text { sis }^{\mathrm{a}}\end{array}$ & $\begin{array}{l}\text { non-miss, } \mathrm{n} \\
\text { mean } \\
\text { SE }\end{array}$ & $\begin{array}{r}176 \\
89.93 \\
4.763\end{array}$ & $\begin{array}{c}163 \\
109.41 \\
6.082\end{array}$ & $\begin{array}{r}93 \\
124.43 \\
8.951\end{array}$ & $\begin{array}{r}66 \\
113.98 \\
10.227\end{array}$ & $\begin{array}{l}1 \text { vs. } 2(p=0.042) \\
1 \text { vs. } 3(p=0.002)\end{array}$ \\
\hline M stage ${ }^{b}$ & $\begin{array}{l}\text { non-miss, n } \\
\text { M0, \% } \\
\text { M1, \% }\end{array}$ & $\begin{array}{r}169 \\
82.25 \\
17.75\end{array}$ & $\begin{array}{r}146 \\
71.23 \\
28.77 \\
\end{array}$ & $\begin{array}{r}89 \\
67.42 \\
32.58 \\
\end{array}$ & $\begin{array}{r}60 \\
85.00 \\
15.00\end{array}$ & $\begin{array}{l}1 \text { vs. } 2(\mathrm{p}=0.023) \\
1 \text { vs. } 3(\mathrm{p}=0.008) \\
2 \text { vs. } 4(\mathrm{p}=0.050)\end{array}$ \\
\hline Lung metastasis ${ }^{\mathrm{b}}$ & $\begin{array}{l}\text { non-miss, } n \\
\text { no, } \% \\
\text { yes, } \%\end{array}$ & $\begin{array}{r}176 \\
82.95 \\
17.05\end{array}$ & $\begin{array}{r}163 \\
83.44 \\
16.56\end{array}$ & $\begin{array}{r}93 \\
69.89 \\
30.11\end{array}$ & $\begin{array}{r}66 \\
89.39 \\
10.61\end{array}$ & $\begin{array}{l}1 \text { vs. } 3(\mathrm{p}=0.019) \\
2 \text { vs. } 3(\mathrm{p}=0.017) \\
3 \text { vs. } 4(\mathrm{p}=0.004)\end{array}$ \\
\hline Receptor status $\mathrm{ER}^{\mathrm{c}}$ & $\begin{array}{l}\text { non-miss, } \mathrm{n} \\
\text { negative, } \% \\
\text { positive, } \%\end{array}$ & $\begin{array}{r}176 \\
0.00 \\
100.00\end{array}$ & $\begin{array}{r}163 \\
0.61 \\
99.39 \\
\end{array}$ & $\begin{array}{r}92 \\
3.26 \\
96.74 \\
\end{array}$ & $\begin{array}{r}66 \\
0.00 \\
100.00\end{array}$ & 1 vs. $3(p=0.040)$ \\
\hline Receptor status $\mathrm{PR}^{\mathrm{c}}$ & $\begin{array}{l}\text { non-miss, } \mathrm{n} \\
\text { negative, } \% \\
\text { positive, } \%\end{array}$ & $\begin{array}{r}175 \\
11.43 \\
88.57\end{array}$ & $\begin{array}{r}161 \\
9.94 \\
90.06\end{array}$ & $\begin{array}{r}92 \\
19.57 \\
80.43\end{array}$ & $\begin{array}{r}66 \\
9.09 \\
90.91\end{array}$ & 2 vs. $3(p=0.036)$ \\
\hline
\end{tabular}

${ }^{a} p$ values based on Wilcoxon rank sum statistic.

${ }^{\mathrm{b}} \mathrm{p}$ values based on Fisher's exact test.

${ }^{c} \mathrm{p}$ values based on Mantel-Haenszel $\chi^{2}$ statistic.

$d_{p}$ value of comparison only given for comparison with statistical significant ( $p$ value $\leq 0.05$ ).

$\mathrm{BMI}=$ Body mass index; ECOG = Eastern Cooperative Oncology Group; SE = standard error; ER = estrogen receptor; PR = progesterone receptor.

However, the placement of exemestane in the treatment sequence was generated from data from this cohort, and this information was described as part of the disease management parameters. As the patient numbers for each line of palliative treatment were small in the exemestane cohort, effectiveness analyses for the secondary endpoints were of a descriptive nature only and a formal statistical comparison of effectiveness endpoints across types of therapy was not undertaken.

All safety and tolerability data are presented in a purely descriptive manner. The statistical analysis was performed using SAS v9.3 (Cary, NC, USA) under Windows 7.

\section{Results}

\section{Demographics}

Although the revised target enrolment was $570 \mathrm{pa}-$ tients, recruitment was stopped at 537 patients after 30 months in line with the protocol amendment. Of these, 504 patients met the inclusion and exclusion criteria and were registered. 6 patients had no tumor anamnesis; as such, 498 patients were evaluable for statistical analysis (online suppl. fig. 1; for all online suppl. material, see www.karger.com/doi/10.1159/00493882). 
There were no significant differences in demographic and key baseline characteristics of study patients between treatment groups (summarized in table 1). The mean age of patients was 67.4 years for fulvestrant and 67.7 years for exemestane. At the date of study entry, a vast majority of patients (87\% fulvestrant any line; $77.3 \%$ exemestane any line) had metastatic disease. Metastases to bone were the most frequent in both groups (61.6\% fulvestrant any line; $56.1 \%$ exemestane any line), followed by the lungs (19.7\% fulvestrant any line; $10.6 \%$ exemestane any line) and lymph nodes (15.5\% fulvestrant any line; $12.1 \%$ exemestane any line). Overall, $99 \%$ of patients were ER+ and $87.1 \%$ were $\mathrm{PR}+;<20 \%$ were HER $2 /$ neu positive (table 1). Over $80 \%$ of patients in each treatment group had an Eastern Cooperative Oncology Group performance status of $0-1$, even in the $3 \mathrm{~L}$ group (table 2).

In total, $24.9 \%$ of the evaluable patients had primary advanced or metastatic breast cancer and $75.1 \%$ showed recurrent breast cancer. For $71.5 \%$ of all patients, prior treatment was documented; prior treatment included surgery (in $33.1 \%$ of all patients), radiation therapy (33.5\%), and systemic treatment (65.7\%). Concomitant diseases were documented for $73.3 \%$ of the evaluable patients. The most common comorbidities were cardiovascular system diseases (in $51.2 \%$ of all patients), followed by metabolic diseases (in $29.7 \%$ of all patients) such as diabetes and thyroid disorders.

On study, $86.7 \%$ of patients received fulvestrant $(1 \mathrm{~L}$, $2 \mathrm{~L}, 3 \mathrm{~L}$ ) and $13.3 \%$ exemestane (online suppl. fig. 2). At the end of the study, $24.9 \%$ of patients continued treatment. Treatment discontinuation was documented for $65.1 \%$ of patients. The main reason for treatment discontinuation was progression of disease $(66 \%, 214 / 324$ patients). For $10 \%$ of patients, no information on further treatment was provided.

\section{Exploration of Real-Life Data on Epidemiology and Management}

Differences in patient characteristics, disease stage, and clinical management decisions as a function of palliative treatment line for fulvestrant or treatment with exemestane were assessed. Variables with significant correlation are shown in table 2 . The only significantly different parameter between all fulvestrant groups and the exemestane group was vascular comorbidity at baseline. Patients in the exemestane group suffered more often from vascular comorbidities, such as thromboembolism or peripheral artery occlusive disease than patients taking fulvestrant.

\section{Efficacy}

TTP for Patients Treated with Fulvestrant 500 mg

Patients on $1 \mathrm{~L}$ palliative treatment experienced a longer TTP compared with patients on $2 \mathrm{~L}$ or $3 \mathrm{~L}$ treatment.

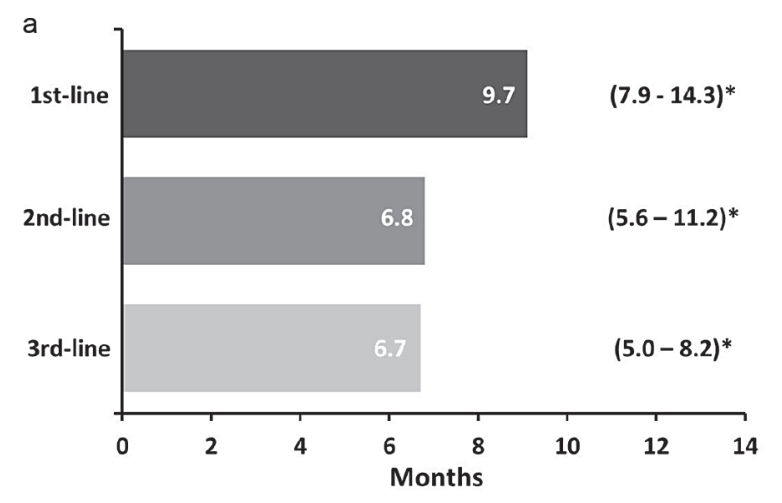

$* 95 \% \mathrm{Cl}$ (confidence interval)

b

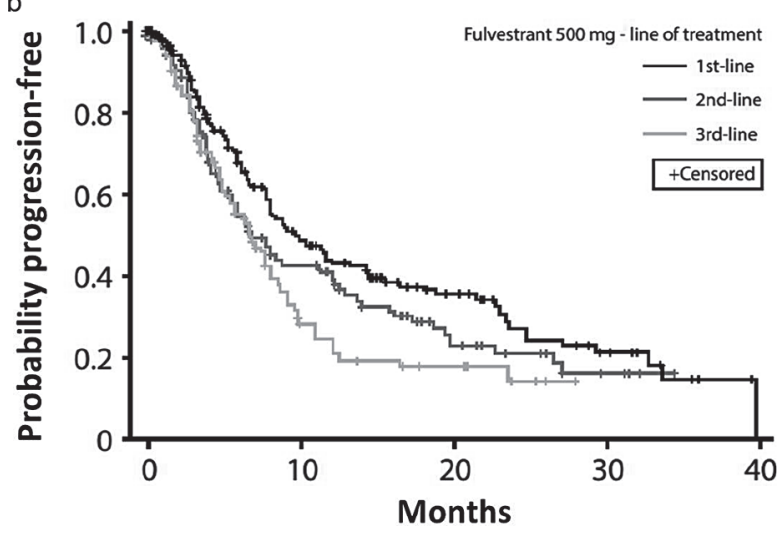

Fig. 1. a, b Time to progression by line of fulvestrant $500 \mathrm{mg}$ treatment.

Median TTP was 9.7 months in patients treated with fulvestrant $500 \mathrm{mg}$ at $1 \mathrm{~L}, 6.8$ months at $2 \mathrm{~L}$, and 6.7 months at $3 \mathrm{~L}$ (fig. 1a). A comparison between fulvestrant $500 \mathrm{mg}$ $1 \mathrm{~L}$ treatment and $2 \mathrm{~L}$ or $3 \mathrm{~L}$ showed that early initiation of treatment prolonged TTP (hazard ratio 1.26; $95 \%$ CI $1.08-1.48 ; \mathrm{p}=0.0042$, Cox regression analysis, proportional hazard assumption fulfilled with $\mathrm{p}>0.9$ ) (fig. 1b). Cox regression analysis was used to determine the prognostic factors that could influence the risk of progressive disease. The risk tendentially increased with line of palliative treatment (hazard ratio 1.163; 95\% CI 0.942-1.435; $\mathrm{p}=0.1596)$. The only statistically relevant prognostic factors for progression were 'age class' $(<65 / \geq 65$ years) and whether the patient had experienced disease progression after prior ET (yes/no) $(\mathrm{p}<0.05$, proportional hazard assumption fulfilled with $\mathrm{p}>0.5$ ): patients aged $\geq 65$ (hazard ratio $0.656 ; 95 \%$ CI $0.510-0.844 ; \mathrm{p}=0.0010$ ) and those who experienced disease progression after their last ET (hazard ratio 1.830; 95\% CI 1.189-2.818; $\mathrm{p}=0.0061$ ) had a higher risk compared with patients aged $<65$ years or those who did not experience disease progression after their last endocrine treatment. 


\section{Patient Outcomes by Line of Fulvestrant $500 \mathrm{mg}$}

Treatment

Median PFS was 9.1 months for patients receiving fulvestrant $1 \mathrm{~L}$ compared with 6.8 months for $2 \mathrm{~L}$ and 6.7 months for $3 \mathrm{~L}$ (online suppl. table 1). Patients on fulvestrant $1 \mathrm{~L}$ had higher frequencies of OR than patients on fulvestrant $2 \mathrm{~L}$ or $3 \mathrm{~L}$. As such, the ORR was greater in patients on fulvestrant $1 \mathrm{~L}(25 \%)$ than in patients on fulvestrant $2 \mathrm{~L}(9.2 \%)$ or $3 \mathrm{~L}(10.8 \%)$. CBR was higher for patients in the $1 \mathrm{~L}$ treatment group than for patients in the 2 L or 3 L group: 29 versus 23.9 and $24.7 \%$, respectively (online suppl. table 2).

\section{Patient Outcomes with Exemestane Treatment}

For exemestane, both median TTP and median PFS were 25.4 months (online suppl. table 1); $12.1 \%$ patients experienced an OR $(n=8)$ and a CBR of $30.3 \%(n=20$; online suppl. table 2).

\section{Safety}

About 25\% of patients in each group exhibited at least $1 \mathrm{AE}$ (combined treatment-related and non-treatmentrelated AEs and serious AEs (SAEs)), and about half of all AEs were SAEs (online suppl. table 3). Most AEs were grade 1 or 2 ; only 2 patients had grade 4 . There were no significant differences in drug-related AEs or SAEs between fulvestrant $500 \mathrm{mg} 1 \mathrm{~L}, 2 \mathrm{~L}$, and $3 \mathrm{~L}$, respectively. The most frequently reported treatment-related AEs in each group are summarized in online supplementary table 4. Of note, drug-related musculoskeletal and connective tissue disorders were noticeably lower in the fulvestrant group (any line) versus the exemestane group (3.9 vs. 7.6\%; online suppl. table 4). No patients receiving fulvestrant as $1 \mathrm{~L}$ or $2 \mathrm{~L}$ palliative treatment had their dose reduced because of an $\mathrm{AE} /$ decision of the investigator; 1 patient receiving fulvestrant as $3 \mathrm{~L}$ palliative treatment had the dose reduced for this reason.

Overall, 70 patients had at least 1 SAE documented; in the majority of cases, there was only 1 SAE per patient. The main classification for an SAE was 'hospitalization or prolongation of hospitalization'. Only 7 documented SAEs (1.4 vs. $1.5 \%)$ were deemed to be associated with fulvestrant or exemestane treatment, respectively (online suppl. table 3). Treatment discontinuation due to AEs and SAEs occurred more often with exemestane than with fulvestrant: 7.6 versus $4.5,2.5$ and $3.2 \%$ of patients for $1 \mathrm{~L}, 2 \mathrm{~L}$ and $3 \mathrm{~L}$, respectively (online suppl. table 3 ).

\section{Discussion}

This was a multicenter, prospective, observational NIS in Germany to directly compare the effectiveness of treatment (measured by TTP) with fulvestrant $500 \mathrm{mg}$ accord- ing to line of palliative treatment. In addition, the study sought to gather epidemiological and disease management data on treatment with fulvestrant and exemestane in a real-world palliative care setting. The results obtained in this NIS showed a better outcome in terms of TTP in patients who received fulvestrant as $1 \mathrm{~L}$ palliative treatment compared to those who received it as later-line treatment. These results support the early initiation of treatment with fulvestrant in line with results published for other ETs (namely that $1 \mathrm{~L}$ palliative treatment is the most effective). However, the inferior outcome of any later than first-line therapy is not unexpected since patients receiving additional lines of palliative treatment require it for a variety of poor prognostic reasons, e.g. drug resistance. As shown in this study, statistically relevant factors for TTP were 'age class' and 'disease progression after previous ET (yes/no)'. Median OS was not reached at the time of analysis. For the group of fulvestrant patients as a whole, a median PFS of 8.0 months was determined. As shown for TTP, median time of PFS was longest for patients treated with fulvestrant for $1 \mathrm{~L}$ treatment, compared with $2 \mathrm{~L}$ and $3 \mathrm{~L}$ treatment, with values of 9.1, 6.8 and 6.7 months, respectively. The reduced PFS for $2 \mathrm{~L}$ treatment or beyond may be explained by the fact that dose reductions due to AEs are more often observed in advanced lines of treatment; this may be supported by the fact that the median duration of therapy decreased with treatment line. Surprisingly, patients treated with exemestane had a median PFS of 25.4 months. Such a long period for median PFS with exemestane in clinical trials has not been documented previously [4, 7-9, 13-15]. In the phase III randomized controlled SoFEA trial conducted in postmenopausal women with $\mathrm{HR}+\mathrm{ABC}$ who had progressed on non-steroidal AIs [15], median PFS in 249 patients treated with exemestane was 3.4 months (95\% CI 3.0-4.6); in patients assigned to fulvestrant plus placebo $(\mathrm{n}=231)$ and fulvestrant plus anastrozole $(\mathrm{n}=$ 243), median PFS was 4.8 months (95\% CI 3.6-5.5) and 4.4 months (95\% CI 3.4-5.4), respectively. The TTP in patients treated with exemestane was also 25.4 months in ACT-FASTER. As with PFS, a TTP of this duration has not been reported in other clinical trials of exemestane. In a phase III randomized trial that compared exemestane $25 \mathrm{mg}$ plus anastrozole $1 \mathrm{mg}$ in postmenopausal women with metastatic, progressive or locally recurrent, inoperable, HR+ breast cancer, the median TTP in exemestane recipients was 13.8 months (95\% CI 10.8-16.5) [16]. Similarly, in an open-label, randomized phase II study that compared exemestane and anastrozole as first-line hormone therapy in postmenopausal women with $\mathrm{HR}+$ ABC, the median TTP with exemestane was 6.1 months (95\% CI 2.5-9.6) [17].

A contributing factor to the unexpected exemestane result may be the small number of patients $(n=66)$ who
406

Breast Care 2019;14:401-408 DOI: $10.1159 / 000493882$
Maass/Ostermann/Possinger/Klein/ Tesch/Mühlenhoff/Bauerschlag 
received this treatment. Although study entry was only possible after pre-specification of endocrine treatment, the recruitment of patients for the exemestane group was fairly modest and the baseline characteristics of this small population may have biased the results. Documentation bias might also have influenced the results, as in the exemestane group no treatment lines were captured; instead treatment line was estimated based on documented prior cancer therapies. The results may also have been affected by incorrect exposure data because of unreliable patient adherence information and the fact that the visit schedules differed between agents. While patients receiving fulvestrant were seen regularly by their physician, exemestane-treated patients were seen less frequently, meaning the possibility of a delayed diagnosis of progression for these patients. Taken together, all of the above factors most likely impair the representativeness of the exemestane efficacy outcomes within this study. This fact should be considered when interpreting these data.

There were no unexpected drug reactions. Only $1 \mathrm{SAE}$ with a fatal outcome was classified as related to fulvestrant, and death was mainly due to disease progression. The other reasons documented were: death from heart failure, renal failure, and unknown cause. The safety evaluation was solely assessed according to the documented AEs and SAEs and no additional laboratory or investigational parameters were required in the NIS. This may be the reason why no increased live enzyme values were reported as AEs, despite it being listed as a very common side effect in the Summary of Product Characteristics for fulvestrant.

Differences in patient characteristics, disease stage, and clinical management decisions were analyzed as a function of lines of therapy with fulvestrant and exemestane. For the majority of the analyzed parameters, the differences between treatment groups were not statistically significant.

The study was limited in terms of the potential biases discussed previously. In addition, there was a betweengroup difference in the follow-up of the 2 groups of patients as a consequence of how often treatment was administered. Namely, patients receiving fulvestrant had monthly visits to receive their injection, whereas patients receiving exemestane only had to visit their doctor on a 3-monthly basis (the period for which tablets were provided in a single pack). This imbalance may explain, at least in part, why TTP was longer with exemestane versus fulvestrant (i.e., TTP could have been detected earlier in the fulvestrant cohort because patients were seen more frequently). The described study limitations should not detract from the strengths of the study. Specifically, due to the study's non-interventional nature, participants were representative of 'typical' postmenopausal women with $\mathrm{HR}+\mathrm{ABC}$ in Germany, yielding real-world data on the use of $500 \mathrm{mg}$ fulvestrant. Patients were treated under daily routine conditions, and treating physicians were wholly responsible for the selection of subjects, diagnostic procedures, routine assessments, and/or therapeutic decisions, according to the routine procedures of the study site. Several trials of fulvestrant, including the SoFEA trial, utilized a dose of $250 \mathrm{mg}[15,18,19]$, as per the standard of care at the time the studies were conducted; however, improved efficacy of fulvestrant at a dose of $500 \mathrm{mg}$ versus $250 \mathrm{mg}$ (in the absence of increased toxicity) was demonstrated in the CONFIRM clinical trial [6].

\section{Conclusion}

Fulvestrant and exemestane can be administered successfully to patients under routine conditions, and both medications are well tolerated. TTP was longest in patients treated with fulvestrant $500 \mathrm{mg}$ at $1 \mathrm{~L}$ compared with $2 \mathrm{~L}$ and $3 \mathrm{~L}$ in the palliative care setting.

\section{Online Supplemental Material}

Suppl. table 1. Progression-free survival.

Suppl. table 2. Tumor response.

Suppl. table 3. Number of patients with AEs, SAEs and ADRs.

Suppl. table 4. Most frequently reported AEs related to treatment with fulvestrant or exemestane (AE and SAE data combined) - incidence of AE by group.

Suppl. fig. 1. Patient distribution.

Suppl. fig. 2. Proportion of patients treated by therapy and treatment line.

To access the supplemental material please refer to $w w w . k a r g-$ er.com/?DOI=493882.

\section{Acknowledgement}

The authors thank Kerry Acheson PhD, CMPP ${ }^{\mathrm{TM}}$ of iMed Comms an Ashfield Company, part of UDG Healthcare plc, and Sonja Hartmann, Alcedis GmbH, Giessen, Germany, for providing medical writing services. Medical writing services were funded by AstraZeneca. The authors thank the investigators who participated in this study.

\section{Consent for Publication}

Not applicable.

\section{Availability of Data and Material}

The data that support the findings of this study can be requested from the study sponsor, AstraZeneca, via the Data Request Portal (astrazenecagroup-dt.pharmacm.com/DT/Home). The request will be evaluated and reviewed by AstraZeneca on a case-by-case basis. 


\section{Funding}

The study and medical writing assistance for preparation of this manuscript was funded by AstraZeneca.

\section{Authors' Contributions}

$\mathrm{PK}, \mathrm{NM}, \mathrm{HO}, \mathrm{KP}$, and HT designed the study. NM was the coordinating investigator of this study. NM, HO, KP, and HP were members of the steering committee. NM and HT were involved in the acquisition of data. PK performed the statistical analyses. DB,
$\mathrm{PK}, \mathrm{LM}, \mathrm{NM}, \mathrm{HO}, \mathrm{KP}$, and HT were involved in the interpretation of data, manuscript drafting, and review and revision of the manuscript. All authors read and approved the final manuscript.

\section{Disclosure Statement}

$\mathrm{PK}, \mathrm{HO}, \mathrm{HT}$ received remuneration from AstraZeneca. LM is an employee of AstraZeneca. HO and DB have undertaken consultant/advisory roles, and $\mathrm{HO}$ has received funding from and owns stocks in AstraZeneca. NM and KP declare that they have no competing interests.

\section{References}

1 WHO: GLOBOCAN 2012: estimated cancer incidence, mortality and prevalence worldwide in 2012. globocan.iarc.fr/; accessed 30 May 2018.

-2 Migliaccio I, Malorni L, Hart CD, et al.: Endocrine therapy considerations in postmenopausal patients with hormone receptor positive, human epidermal growth factor receptor type 2 negative advanced breast cancers. BMC Med 2015;13:46.

3 AGO Breast Committee: Diagnosis and treatment of patients with primary and metastatic breast cancer. Guidelines 2018. ago-online. de; accessed 30 May 2018.

44 Paridaens RJ, Dirix LY, Beex LV, et al: Phase III study comparing exemestane with tamoxifen as first-line hormonal treatment of metastatic breast cancer in postmenopausal women: the European Organisation for Research and Treatment of Cancer Breast Cancer Cooperative Group. J Clin Oncol 2008;26:48834890.

5 EMA: Faslodex - EMEA/H/C/000540 T/0063. Summary of Product Characteristics, AstraZeneca. www.ema.europa.eu/docs/en_ GB/document_library/EPAR_-_Product_Information/human/000540/WC500021174. pdf; accessed 30 May, 2018.

6 Di Leo A, Jerusalem G, Petruzelka L, et al: Results of the CONFIRM phase III trial comparing fulvestrant $250 \mathrm{mg}$ with fulvestrant 500 $\mathrm{mg}$ in postmenopausal women with estrogen receptor-positive advanced breast cancer. J Clin Oncol 2010;28:4594-4600.

7 Chernozemsky I, Kalinov K, Tzekov H, et al: Randomized phase III trial of exemestane or tamoxifen in first-line hormonal treatment of postmenopausal women with metastatic breast cancer. Breast Cancer Res Treat 2007;S119:abstr 2102.

-8 Kaufmann M, Bajetta E, Dirix LY, et al: Exemestane is superior to megestrol acetate after tamoxifen failure in postmenopausal women with advanced breast cancer: results of a phase III randomized double-blind trial. The Exemestane Study Group. J Clin Oncol 2000; 18:1399-1411.

9 Lonning PE: Exemestane: a review of its clinical efficacy and safety. Breast 2001;10:198208.

10 Kuter I, Gee JM, Hegg R, et al: Dose-dependent change in biomarkers during neoadjuvant endocrine therapy with fulvestrant: results from NEWEST, a randomized phase II study. Breast Cancer Res Treat 2012;133:237246.

11 Robertson JF, Llombart-Cussac A, Rolski J, et al: Activity of fulvestrant $500 \mathrm{mg}$ versus anastrozole $1 \mathrm{mg}$ as first-line treatment for advanced breast cancer: results from the FIRST study. J Clin Oncol 2009;27:4530-4535.

12 Exemestan, Pfizer: Summary of Product Characteristics. www.fachinfo.de; accessed 30 May, 2019.

13 Chia S, Gradishar W, Mauriac L, et al: Double-blind, randomized placebo controlled trial of fulvestrant compared with exemestane after prior nonsteroidal aromatase inhibitor therapy in postmenopausal women with hormone receptor-positive, advanced breast cancer: results from EFECT. J Clin Oncol 2008; 26:1664-1670.

14 Zucchini G, Geuna E, Milani A, et al: Clinical utility of exemestane in the treatment of breast cancer. Int J Womens Health 2015;7: 551-563.

15 Johnston SR, Kilburn LS, Ellis P, et al: Fulvestrant plus anastrozole or placebo versus exemestane alone after progression on non-steroidal aromatase inhibitors in postmenopausal patients with hormone receptor-positive locally advanced or metastatic breast cancer (SoFEA): a composite, multicentre, phase 3 randomised trial. Lancet Oncol 2013;14:989-998.

16 Iwata H, Masuda N, Ohno S, et al: A randomized, double-blind, controlled study of exemestane versus anastrozole for the first-line treatment of postmenopausal Japanese women with hormone-receptor-positive advanced breast cancer. Breast Cancer Res Treat 2013; 139:441-451.

17 Llombart-Cussac A, Ruiz A, Anton A, et al: Exemestane versus anastrozole as front-line endocrine therapy in postmenopausal patients with hormone receptor-positive, advanced breast cancer: final results from the Spanish Breast Cancer Group 2001-03 phase 2 randomized trial. Cancer 2012;118:241247.

18 Bergh J, Jonsson PE, Lidbrink EK, et al: FACT: an open-label randomized phase III study of fulvestrant and anastrozole in combination compared with anastrozole alone as first-line therapy for patients with receptor-positive postmenopausal breast cancer. J Clin Oncol 2012;30:1919-1925.

19 Mehta RS, Barlow WE, Albain KS, et al: Combination anastrozole and fulvestrant in metastatic breast cancer. N Engl J Med 2012;367: 435-444. 